\title{
Late results of right ventricular outflow tract reconstruction with Björk-Shiley valved conduits
}

\author{
W MELDRUM-HANNA, T CARTMILL, D JOHNSON, J CELERMAJER, \\ R HAWKER
}

From the Basser Institute of Cardiology, Royal Alexandra Hospital for Children, Camperdown, New South

Wales, Australia

SUMMARY Between 1971 and December 1976, 27 children with congenital heart disease underwent right ventricular outflow tract reconstruction with conduits incorporating a Björk-Shiley valve. The conditions corrected were pulmonary atresia with ventricular septal defect (14 patients), truncus arteriosus (6 patients), and complex disease ( 7 patients). At operation the children were aged from 12 days to 16 years (five patients were less than one year old). Overall mortality for the group was high (52\%). There were nine early deaths and five late ones. Actuarial survival till death or reoperation was $55 \%$ at four years, $35 \%$ at eight years, and $28 \%$ at 12 years. Ten children subsequently underwent reoperation for conduit stenosis caused by neointimal proliferation and valve obstruction. The new conduits incorporated a biological valve.

Mortality was highest in patients aged less than one year, and in those with truncus arteriosus, severe pulmonary hypertension, or complex heart disease. Mechanical valves should be avoided in conduit reconstruction of the right ventricular outflow tract for congenital heart disease.

In 1971 we started to use a Björk-Shiley tilting disc aortic valve prosthesis incorporated into a Dacron vascular graft for the repair of various complex cardiac malformations including pulmonary atresia, transposition of the great arteries with ventricular septal defect, and truncus arteriosus. Initial experience with this valved conduit was promising; there was no valve dysfunction for up to three years postoperatively. ${ }^{1}$

We now present our long term experience with this conduit in 27 children.

\section{Patients and methods}

Between March 1971 and December 1976, 27 children underwent right ventricular outflow tract reconstruction with Björk-Shiley valved conduit. Fourteen children with pulmonary atresia and ventricular septal defect underwent repair. Six infants with truncus arteriosus also had conduit recon-

Requests for reprints to Mr T Cartmill, Basser Institute of Cardiology, Royal Alexandra Hospital for Children, Camperdown, NSW, Australia.

Accepted for publication 18 November 1985 struction of the right ventricular outflow tract. Other forms of complex congenital disease were also repaired by this technique including tetralogy of Fallot, double outlet right ventricle, single ventricle, and transposition of the great arteries with ventricular septal defect (Table 1).

Seventeen $(63 \%)$ of the children had had previous systemic to venous shunts in an attempt to relieve cyanosis and promote growth in the pulmonary circulation (Blalock-Taussig eight patients, Waterston seven patients, Potts two patients). Pulmonary artery banding had been performed to reduce the pulmonary circulatory flow in two infants with truncus arteriosus.

Table 1 Indications for valve implant in 27 patients

\begin{tabular}{lr}
\hline Indication & No \\
\hline Truncus & 6 \\
TGA with VSD & 1 \\
Pulmonary atresia with VSD & 14 \\
Tetralogy of Fallot & 1 \\
Complex: DORV & 2 \\
& Taussig-Bing \\
$\quad$ Single ventricle & 1 \\
\hline
\end{tabular}

TGA, transposition of the great arteries; VSD, ventricular septal defect; DORV, double outlet right ventricle. 
Patients were aged from 12 days to 16 years. Five $(18 \%)$ children were aged less than one year at operation.

\section{TECHNIQUE}

Routine cardiopulmonary bypass with hypothermic circulatory arrest was performed in all patients. We have described this technique elsewhere. ${ }^{12}$ The Björk-Shiley prosthesis was fixed into the conduit during the period of core cooling, usually by means of a continuous suture technique. We used twenty three straight tubular grafts, ranging from 16 to 28 $\mathrm{mm}$ in diameter, and four bifurcation grafts. The valve prosthesis size ranged from $17 \mathrm{~mm}$ to $27 \mathrm{~mm}$, and valves with pyrolytic carbon discs were used in all except one of the patients. Twenty one $(77 \%)$ children had a valve size $\geqslant 21 \mathrm{~mm}$.

After systemic cooling to $17-18^{\circ} \mathrm{C}$ repair was performed during a period of circulatory arrest which lasted from 15-77 minutes (mean 57 minutes).

We opened the right ventricular outflow (usually longitudinally or parallel to major coronary branches), avoiding damage to major coronary arteries. Ventricular septal defects were closed with a patch of Dacron. The conduit was then cut to length and the distal anastomosis was performed either to the main pulmonary artery, when this was present, or to the confluence of right and left pulmonary arteries. In two patients the bifurcation grafts had to be anastomosed separately to each pulmonary artery, leaving the division of the graft astride the ascending aorta (truncus).

The proximal anastomosis was constructed after the graft end had been cut obliquely to allow the graft to assume a gentle curve after it had been sutured to the right ventricle; this was done to prevent conduit compression or distortion after sternal closure. Warfarin anticoagulation was not routinely used in all patients.

\section{Results}

\section{MORTALITY}

Early-Nine children died at or soon after operation (Table 2). Three children, all with truncus II, aged less than 4 months died at operation; two of them were moribund before operation. One child with pulmonary atresia and ventricular septal defect died after unrecognised injury to the left anterior descending artery. No death was due to valve dysfunction.

Late-Five children died more than $\mathbf{3 0}$ days after operation (Table 2). Two children (with double outlet right ventricle and pulmonary atresia with ventricular septal defect) died suddently at 3 months and $3 \frac{1}{2}$ years respectively, presumably from an arrhythmia. In both cases the valved conduit was examined at necropsy and found to be functioning adequately.

One child (with pulmonary atresia and ventricular septal defect) underwent reoperation four years later because of intimal flap proliferation and conduit stenosis. This child subsequently died at a second reoperation procedure (for a failed Hancock bioprosthesis) eight years after the original operation. Another child (pulmonary atresia with ventricular septal defect) died suddenly at recatheter study for right ventricular outflow tract obstruction (six years after operation). Necropsy showed a massive neointimal prolapse and acute Björk-Shiley valve obstruction.

Actuarial survival till death or reoperation was $55 \%$ at four years, $35 \%$ at eight years, and $28 \%$ at 12 years (Fig. 1).

\section{REOPERATION}

Of the 18 children who survived operation, 10 $(55 \%)$ subsequently underwent reoperation for 0 right ventricular outflow tract obstruction. All these children had important neointimal proliferation in the conduit; in two children the Björk-Shiley valve was both partly obstructed and fixed in a semi-open position.

In five children the new conduit contained a Hancock bioprosthesis (usually a $25 \mathrm{~mm}$ one). The remaining five had Carpentier-Edwards porcine bioprostheses (range $22-25 \mathrm{~mm}$ ). Of the patients undergoing reoperation, two subsequently had further repeat operations. One child (pulmonary atresia with ventricular septal defect) died at reoperation for right ventricular outflow tract obstruction in a Carpentier-Edwards conduit; the other child (pulmonary atresia with ventricular septal defect) also underwent successful replacement of a Hancock prosthesis with a Carpentier-Edwards bioprosthesis because of staphylococcal endocarditis.

Only four patients are still alive with the original Björk-Shiley valve conduit in situ. Two of these have mild degrees of right ventricular outflow tract obstruction, with slightly increased right ventricular pressures $(16-20 \mathrm{~mm})$ at restudy.

\section{Discussion}

Both valved and non-valved conduits have been 0 used successfully for right ventricular outflow tract $o$ reconstruction. ${ }^{3-7}$ Our group of 27 children under- $\mathbb{D}$ going right ventricular outflow tract reconstruction $\stackrel{\oplus}{?}$ with a Björk-Shiley valved conduit represents a $T$ unique long term experience of a mechanical valve in this position.

The size of the Björk-Shiley valves ranged from 
Table 2 Early and late mortality in children undergoing operation

\begin{tabular}{|c|c|c|}
\hline Pathology & Age at operation & Cause \\
\hline $\begin{array}{l}\text { Early mortality }(n=9): \\
\text { Truncus } \\
\text { Truncus } \\
\text { Truncus } \\
\text { Truncus } \\
\text { Pulmonary atresia/VSD } \\
\text { Pulmonary atresia/VSD } \\
\text { Single ventricle } \\
\text { Single ventricle } \\
\text { DORV }\end{array}$ & $\begin{array}{l}12 \text { days } \\
3 \mathrm{mnth} \\
4 \mathrm{mnth} \\
6 \mathrm{yr} \\
4 \mathrm{yr} \\
4 \mathrm{yr} \\
12 \mathrm{yr} \\
16 \mathrm{yr} \\
5 \mathrm{yg} \mathrm{yr}\end{array}$ & $\begin{array}{l}\text { Low output } \\
\text { Low output } \\
\text { Low output } \\
\text { Pulmonary oedema } \\
\text { LAD injury } \\
\text { Low output } \\
\text { Low output } \\
\text { Low output } \\
\text { Atrioventricular dissociation }\end{array}$ \\
\hline $\begin{array}{l}\text { Late mortality }(\mathrm{n}=5) \text { : } \\
\text { Pulmonary atresia/VSD } \\
\text { Pulmonary atresia/VSD } \\
\text { Pulmonary atresia/VSD } \\
\text { Pulmonary atresia/VSD } \\
\text { DORV }\end{array}$ & $\begin{array}{rl}1 & \mathrm{yr} \\
2 & \mathrm{yr} \\
5 & \mathrm{yr} \\
7 & \mathrm{yr} \\
13 \mathrm{yr}\end{array}$ & $\begin{array}{l}\text { Pulmonary hypertension } \\
\text { ? Arrhythmia } \\
\text { Two repeat operations } \\
\text { Valve obstruction } \\
\text { ? Arrhythmia }\end{array}$ \\
\hline
\end{tabular}

VSD, ventricular septal defect; DORV, double outlet right ventricle; LAD, left anterior descending coronary artery.

17 to $27 \mathrm{~mm}$. Most of the valves implanted (21 patients) were in sizes consistent with adult needs (size $21 \mathrm{~mm}$ ), and would certainly be adequate for growth of the patients. Although the children were not routinely anticoagulated, valve thrombosis or pulmonary embolism was not clinically apparent.

Mortality for the whole group was high $(52 \%)$. Actuarial survival (till death or reoperation) was $55 \%$ at four years and $28 \%$ at 12 years. Operative mortality was high (33\%), but, bearing in mind the severity of disease, the age of the patients, and the lack of sophisticated techniques of myocardial preservation (except deep hypothermia) when these operations were done, the results are not unreasonable. Early mortality was worst for children with truncus (four cases) or complex disease (three cases) and those in whom pulmonary hypertensive disease (four cases) was developing. Although the relation between mortality and age at operation is not statis-

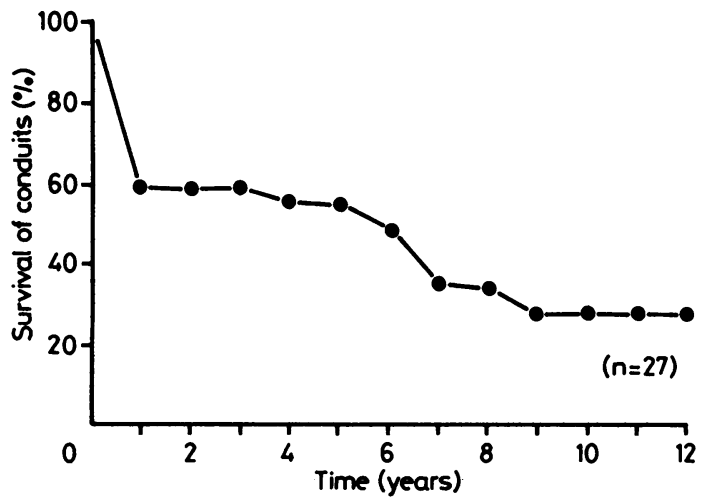

Fig. 1 Actuarial survival till death or reoperation for patients after right ventricular outflow tract reconstruction with conduits with Björk-Shiley valves. tically significant for the total group, three $(60 \%)$ of five patients aged $\leqslant 1$ year died at or soon after operation.

The development of stenosis of the valved conduit and the need for catheter restudy was established clinically by an increase in fatigue, a pulmonary outflow murmur of increasing intensity, and signs of right ventricular overactivity or failure. Some workers have suggested that catheter restudy should be routinely performed after operation as an objective measure of pulmonary tract stenosis. ${ }^{458-10}$

Heck et al have reported catheter data obtained one year or more after operation; $57 \%$ of their patients had a moderate to severe pressure gradient across the valved conduits at catheter restudy (both homograft and heterografts), despite the fact that $88 \%$ of them were symptom free. ${ }^{8} \mathrm{We}$ feel that some caution should be exercised. One patient in our series had a sudden fatal valve obstruction after the neointimate peel had been dislodged at catheter restudy. The peel is often only tenuously attached to the Dacron conduit ${ }^{6-811-13}$ and is easily detached and may lead to acute valve obstruction or massive pulmonary embolism. We now routinely assess the outflow tract by means of cross sectional echocardiography before catheter restudy.

Recurrent or residual valved conduit obstruction has many causes: conduit compression, valve stenosis or obstruction, and the development of a neointimal peel causing conduit stenosis. Bailey et al reported that conduit compression between sternum and heart was the commonest cause of right ventricular outflow tract obstruction in their patients (five of 68 patients). ${ }^{14}$ We have not experienced this difficulty in our patients.

The frequency of conduit compression has decreased considerably in later series and this has been due to improvement in surgical technique. 
Compression is best avoided by siting the valve as far distally as possible ${ }^{15}$ and by having the conduit in a reversed " $C$ " location in the mediastinum-to the left with levocardia and to the right side with dextrocardia and levoposition of the aorta. ${ }^{14-16}$ Removal of the posterior table of the sternum has also been suggested, but this should not be necessary if the conduit has been well orientated laterally by the above technique. ${ }^{16}$ None the less whatever technique is used, there seems to be evidence that conduit compression may be related to growth of the heart or to ventricular hypertrophy. ${ }^{8}$

Valvar stenosis or obstruction is common in those conduits that incorporate a heterograft or homograft. Agarwal et al reported that porcine valvar stenosis was the commonest cause of obstruction in their series $(38 \%))^{11}$ In almost all reported series, obstruction has been mainly due to calcific valvar stenosis. ${ }^{\text {17-22 }}$ Calcific stenosis is a well known complication of aortic homografts in the pulmonary position, but this stenosis mainly affects the wall of the homograft and later the valve leaflets. Excellent long term results with aortic homografts for right ventricular outflow tract reconstruction have recently been reported by Ross and Somerville; they reported a low late reoperation rate $(11.5 \%)$ for conduit stenosis (at 10 years) in three of 26 patients followed for more than 10 years. ${ }^{23}$ Stark et al use an aortic homograft as their conduit of choice for the right ventricular outflow tract and they have noted a similar low late reoperation rate (16 out of 170 , $9.4 \%{ }^{24}$ Both groups also implicate the Dacron patch that is used to bridge discontinuity between the homograft and the right ventricle as the cause of obstruction by a neointimal peel. This problem can be avoided by use of an aortic homograft with its anterior leaflet of the mitral valve as a patch. Alternatively, it is easy to use pericardium as a patch ${ }^{2324}$ and thus avoid all prosthetic material in the reconstruction of the right ventricular outflow tract.

In our series the major cause of recurrent right ventricular outflow tract obstruction was the development of a proliferative neointimal peel in the Dacron conduit. It seems that the development of neointimal peel is inevitable. ${ }^{11-1325}$ There is evidence that the valve itself may exacerbate peel formation. ${ }^{13}$

A fibrous peel was present in all of the 10 children undergoing reoperation, and in varying degrees it obstructed the conduit on both sides of the BjörkShiley valve. Small amounts of thrombus, both old and new, were also found in the Björk-Shiley valve mechanism itself: In one case the valve was partly obstructed and fixed in an open regurgitant position by peel prolapse and thrombus. In another case the largest peel was found distal (Fig. 2) to the valve and the proximal peel was thinner and adhered to the

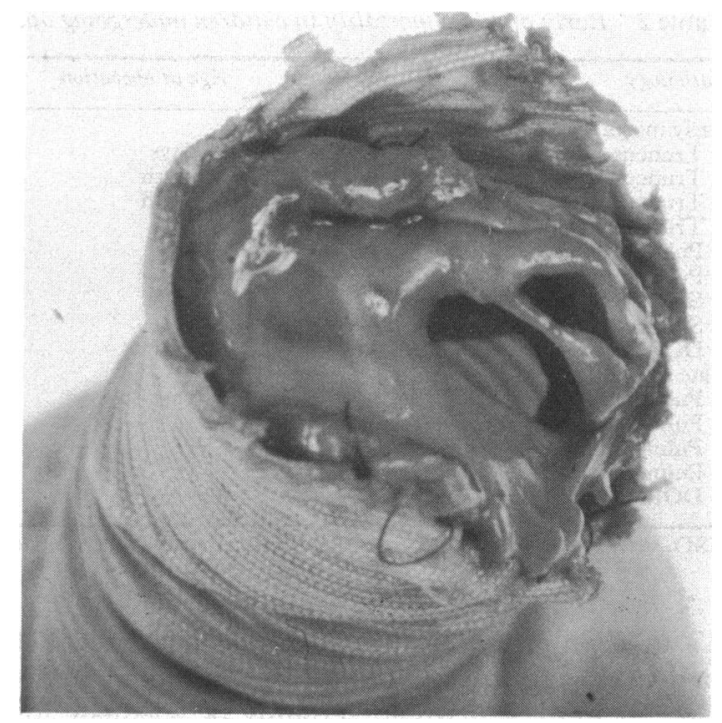

Fig. 2 Thick fenestrated and friable neointimal peel in distal conduit.

\section{Dacron graft.}

The reoperation rate is high ( $52 \%$ of survivors), and compares unfavourably with reported reoperation rates of $0.8 \%-30 \%$ for conduit stenosis in the presence of biological valves. ${ }^{1725}$ Development of this neointimal peel is slow. The time of reoperation varies between four and 10 years (mean five years) and in our experience most patients requiring reoperation present in the fifth postoperative year.

The conduit with Björk-Shiley valve has not performed well in the right ventricular outflow tract because of the inevitable development of neointimal proliferative conduit stenosis with subsequent valve malfunction. Our experience suggests that mechanical valves should be avoided in right ventricular outflow tract reconstruction.

\section{References}

1 Cartmill TB, Celermajer JM, Stuckey DS, Bowdler JD, Johnson DC, Hawker RE. Use of Björk-Shiley tilting disc prosthesis in valved conduits for right ventricular outflow reconstruction. $\mathrm{Br}$ Heart $\mathcal{F}$ 1974; 36: 1106-8.

2 Cartmill TB, Barr PA, Overton JH, et al. Repair of cyanotic heart disease in infancy with hypothermic perfusion and circulatory arrest. Singapore Med f 1973; 14: 254-5.

3 Ross DN, Somerville J. Correction of pulmonary atresia with a homograft valve. Lancet 1966; ii: 1446-7.

4 McGoon DC, Rastelli GC, Wallace RB. Discontinuity between the right ventricle and pulmonary artery: surgical treatment. Ann Surg 1970; 172: 680-9. 
5 Behrendt DM, Kirsh MM, Stern A, Sigmann J, Perry $B$, Sloan $H$. The surgical therapy for pulmonary arteryright ventricular discontinuity. Ann Thorac Surg 1974; 18: 122-37.

6 Moore CH, Martelli V, Ross DN. Reconstruction of right ventricular outflow tract with a valved conduit in 75 cases of congenital heart disease. $\mathcal{f}$ Thorac Cardiovasc Surg 1976; 71: 11-9.

7 Spicer RL, Behrendt D, Crowley DC, et al. Repair of truncus arteriosus in neonates with the use of a valveless conduit. Circulation 1984; 70 (suppl 1): 26-9.

8 Heck HA, Schieken RM, Lauer RM, Doty DB. Conduit repair for complex congenital heart disease. $\mathcal{f}$ Thorac Cardiovac Surg 1978; 75: 806-14.

9 Bisset GS, Schwartz DC, Benzing G, Helmsworth J, Kaplan S. Late results of reconstruction of the right ventricular outflow tract with valved external conduits in children [Abstract]. Am $\mathcal{F}$ Cardiol 1980; 45: 448.

10 Norwood WI, Freed MP, Rocchini AP, Bernhard WF, Castaneda AR. Experience with valve conduits for repair of congenital cardiac lesion. Ann Thorac Surg 1977; 24: 223-32.

11 Agarwal KC, Edwards WD, Feldt RA, Danielson GK, Puga FJ, McGoon DC. Clinicopathological correlates of obstructed right sided porcine valve extracardiac conduits. F Thorac Cardiovasc Surg 1981; 81: 591-601.

12 Agarwal KC, Edwards WD, Feldt RA, Danielson GK, Puga FJ, McGoon DC. Pathogenesis of nonobstructive fibrous peels in right sided porcine valved extracardiac conduits. F Thorac Cardiovasc Surg 1982; 83: 584-9.

13 Fiore AC, Peigh PS, Robinson RJ, Glant MD, King H, Brown JW. Valved and nonvalved right ventricular pulmonary arterial extracardiac conduits. $\mathcal{f}$ Thorac Cardiovasc Surg 1983; 86: 490-7.

14 Bailey WW, Kirklin JW, Bargeron LM, Pacifico AD, Kouchoukos NT. "Late results with synthetic valved external conduits from venous ventricle to pulmonary artery. Circulation 1977; 56 (suppl 2): 73-9.

15 Ebert PA, Robinson SJ, Starger P, Engle MA. Pul- monary artery conduits in infants younger than six months of age. I Thorac Cardiovasc Surg 1976; 72: 351-6.

16 Stewart S. Reconstruction of right ventriculopulmonary artery continuity with a valved external conduit. $\mathcal{F}$ Thorac Cardiovasc Surg 1976; 72: 39-47.

17 Ciaravella JM, McGoon DC, Danielson GK, Wallace RB, Mair DD. Experience with the extracardial conduit. F Thorac Cardiovasc Surg 1979; 78: 920-30.

18 Merin G, McGoon DC. Reoperation after insertion of aortic homograft as a right ventricular outflow tract. Ann Thorac Surg 1973; 16: 122-6.

19 Moodie DS, Mair DD, Fulton RE, Wallace RB, Danielson GK, McGoon DC. Aortic homograft obstruction. F Thorac Cardiovasc Surg 1976; 72: 553-61.

20 Saravalli OA, Somerville J, Jefferson KE. Calcification of aortic homografts used for reconstruction of the right ventricular outflow tract. $\mathcal{f}$ Thorac Cardiovasc Surg 1980; 80: 909-20.

21 Rosenthal A, Rocchini AP, Keane JF, Castaneda AR, Nadas AS. Haemodynamics after surgical repair with right ventricle for pulmonary artery conduit [Abstract]. Circulation 1975; 52 (suppl 2): 102.

22 Geha AS, Laks H, Stansel HC, et al. Late failure of porcine valve heterografts in children. $\mathcal{F}$ Thorac Cardiovasc Surg 1979; 78: 351-64.

23 Ross DN, Somerville J. Fate of the aortic homograft used for reconstruction of the right ventricular outflow tract. Proceedings of the 3rd International Symposium on Cardiac Bioprostheses. London: Yorke Medical, 1985. (in press).

24 Stark J, Merrill W, de Leval M, Macartney FJ, Rees P, Taylor J. Valved conduits in the repair of complex congenital heart defects. Proceedings of $3 r d$ International Symposium on Cardiac Bioprostheses. London: Yorke Medical, 1985. (in press.)

25 Stewart S, Manning J, Alexson C, Harris P. The Hancock external valved conduit. $\mathcal{F}$ Thorac Cardiovasc Surg 1983; 86: 562-9. 